\title{
Effect of Gender, Energetics, and Biomechanics on Swimming Masters Performance
}

\author{
Maria I. Ferreira,,${ }^{1,2}$ Tiago M. Barbosa, ${ }^{2,3}$ Henrique P. Neiva,,${ }^{1,2}$ Carlos C. Marta, $, 2,4$ \\ Mário J. Costa, ${ }^{2,4}$ and Daniel A. Marinho ${ }^{1,2}$ \\ ${ }^{1}$ Department of Sport Sciences, University of Beira Interior, Covilhã, Portugal; ${ }^{2}$ Research Center in Sports, Health and Human \\ Development, Covilhã, Portugal; ${ }^{3}$ National Institute of Education, Nanyang Technological University, Nanyang, Singapore; \\ and ${ }^{4}$ Polytechnic Institute of Guarda, Research Centre for Interior Development, Guarda, Portugal
}

\begin{abstract}
Ferreira, MI, Barbosa, TM, Neiva, HP, Marta, CC, Costa, MJ, and Marinho, DA. Effect of gender, energetics, and biomechanics on swimming masters performance. J Strength Cond Res 29(7): 1948-1955, 2015-The purpose of this study was to analyze the effect of gender and energetics on biomechanics and performance of masters swimmers over 1 season. Twenty-five masters swimmers (14 male and 11 female) were assessed 3 times $\left(\mathrm{TP}_{1}, \mathrm{TP}_{2}\right.$, and $\mathrm{TP}_{3}$ ) during a season (male personal record in 200-m freestyle event: $173.00 \pm 31.41$ seconds: female personal record in 200-m freestyle event: $200.73 \pm 25.02$ seconds). An incremental $5 \times 200-m$ step test was selected to evaluate velocity at $4 \mathrm{mmol} \cdot \mathrm{I}^{-1}$ of blood lactate concentration $\left(v_{4}\right)$, maximal blood lactate concentration after exercise $\left(\mathrm{La}_{\text {peak }}\right)$, maximal oxygen uptake $\left(\dot{\mathrm{V}}_{2} \mathrm{max}\right)$, stroke frequency, stroke length (SL), stroke index (SI), and propelling efficiency of the arm stroke $\left(\eta_{p}\right)$. The 200-m freestyle performance and average swimming velocity $\left(v_{200}\right)$ were also monitored. Significant differences were observed between males and females for the 200-m freestyle performance, SL, SI, and $\mathrm{La}_{\text {peak. Performance }}(205.18 \pm 24.47$ seconds; $197.45 \pm$ 20.97 seconds; $193.45 \pm 18.12$ seconds), SL (1.69 $\pm 0.17 \mathrm{~m}$; $1.79 \pm 0.13 \mathrm{~m} ; 1.78 \pm 0.15 \mathrm{~m}), \mathrm{SI}(1.68 \pm 0.31$ $\mathrm{m}^{2} \cdot \mathrm{c}^{-1} \cdot \mathrm{s}^{-1} ; 1.83 \pm 0.27 \mathrm{~m}^{2} \cdot \mathrm{c}^{-1} \cdot \mathrm{s}^{-1} ; 1.85 \pm 0.27$ $\left.\mathrm{m}^{2} \cdot \mathrm{c}^{-1} \cdot \mathrm{s}^{-1}\right), \eta_{\mathrm{p}}(0.32 \pm 0.04 ; 0.33 \pm 0.03 ; 0.33 \pm 0.04)$, and $\dot{\mathrm{V}}_{2} \max \left(38.71 \pm 3.44 \mathrm{ml} \cdot \mathrm{kg}^{-1} \cdot \mathrm{min}^{-1} ; 43.43 \pm 3.71\right.$ $\left.\mathrm{ml} \cdot \mathrm{kg}^{-1} \cdot \mathrm{min}^{-1} ; 43.95 \pm 7.02 \mathrm{ml} \cdot \mathrm{kg}^{-1} \cdot \mathrm{min}^{-1}\right)$ have changed significantly throughout the season $\left(\mathrm{TP}_{1}, \mathrm{TP}_{2}\right.$, and $\mathrm{TP}_{3}$, respectively) in female swimmers. In male, significant changes were found in $\eta_{p}(0.33 \pm 0.07 ; 0.36 \pm 0.05 ; 0.36 \pm 0.06)$ and $\dot{\mathrm{V}}_{2} \max \left(41.65 \pm 7.30 \mathrm{ml} \cdot \mathrm{kg}^{-1} \cdot \mathrm{min}^{-1} ; 45.19 \pm 6.55\right.$ $\left.\mathrm{ml} \cdot \mathrm{kg}^{-1} \cdot \mathrm{min}^{-1} ; 50.19 \pm 9.65 \mathrm{ml} \cdot \mathrm{kg}^{-1} \cdot \mathrm{min}^{-1}\right)$ over the season $\left(\mathrm{TP}_{1}, \mathrm{TP}_{2}\right.$, and $\mathrm{TP}_{3}$, respectively). Gender presented a significant
\end{abstract}

Address correspondence to Maria I. Ferreira, mines_ferreira@sapo.pt. 29(7)/1948-1955

Journal of Strength and Conditioning Research

(C) 2015 National Strength and Conditioning Association

1948

Journal of Strength and Conditioning Research effect on SL $\left(\mathrm{TP}_{2}: \eta_{\mathrm{p}}^{2}=0.29 ; \mathrm{TP}_{3}: \eta_{\mathrm{p}}^{2}=0.37\right)$, SI $\left(\mathrm{TP}_{2}: \eta_{\mathrm{p}}^{2}=\right.$ $0.25)$, and $\mathrm{La}_{\text {peak }}\left(\mathrm{TP}_{3}: \eta_{\mathrm{p}}^{2}=0.42\right) . v_{4}\left(\mathrm{TP}_{1}: \eta_{\mathrm{p}}^{2}=0.23\right)$, SL (TP : $^{2}$ $\left.\eta_{\mathrm{p}}^{2}=0.46\right)$, SI $\left(\mathrm{TP}_{1}: \eta_{\mathrm{p}}^{2}=0.78 ; \mathrm{TP}_{2}: \eta_{\mathrm{p}}^{2}=0.37 ; \mathrm{TP}_{3}: \eta_{\mathrm{p}}^{2}=0.32\right)$, and $\eta_{\mathrm{p}}\left(\mathrm{TP}_{1}: \eta_{\mathrm{p}}^{2}=0.28\right)$ had a significant effect on performance. Male masters swimmers have better performance, SL, SI, and $\mathrm{La}_{\text {peak }}$ than female counterparts. Female masters swimmers enhanced significantly the 200-m freestyle performance over the season due to the improvement in swimming technique (SL, SI, and $\left.\eta_{p}\right)$ and energetic factors $\left(v_{4}\right.$ and $\dot{V}_{2}$ max). Nonsignificant improvements were observed for the males' performance. Gender has a significant effect on SL, SI, and $\mathrm{La}_{\text {peak. }}$ Therefore, performance is more dependent on technical factors than energetics.

KEY WoRDS aging, season, technique, physiology, front crawl

\section{INTRODUCTION}

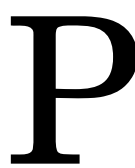

hysical exercise has a positive and meaningful effect on health (8). Nevertheless, aging affects the level of physical activity, and therefore physical fitness, due to a decrease in engagement in physical activity and a trend to train at lower exercise intensities (34). Moreover, with advancing age, structural and functional impairment happens in most of the physiological systems, even in the absence of discernible diseases. So, it is expected that human performances in sports can also be impaired with aging $(8,13,23)$. Research with master athletes provides a good chance to investigate age effects on the metabolic/biomechanic determinants of performance (7), excluding physical inactivity as a potential confounding factor (7).

The reasons behind the participation of master athletes in competitions and in regular exercise are the enjoyment, the health benefits (31), and the best performance. For those reasons, the identification of the factors that influence the swimming performance and the magnitude of their influence is an important aim. Swimming performance is determined by physiologic, biomechanic, and psychological factors whereby the development of these characteristics enhances the possibility of success (1). Therefore, the longitudinal assessment of the performance is important because it enables the analysis of the swimmer progression over a season 
induced by training (11). Considering that master swimmers have less practice sessions in comparison with younger counterparts (29) and that their main focus is the build-up of endurance (34), it is worth to evaluate whether a training program will have impact on energetics and biomechanics. Energetic variables, such as aerobic and anaerobic capacities, can be assessed at the concentration of $4 \mathrm{mmol} \cdot \mathrm{l}^{-1}$ of blood lactate levels $\left(v_{4}\right)$, maximal oxygen consumption $\left(\dot{\mathrm{V}}_{2} \mathrm{max}\right)$, and maximal blood lactate concentration after exercise $\left(\mathrm{La}_{\text {peak }}\right)$, respectively. These variables may be useful tools to monitor the effects of aging on muscle metabolism. The biomechanical parameters are useful indicators of the swimming technique (4) and include the stroke mechanics, such as stroke frequency (SF), stroke length (SL), stroke index $(\mathrm{SI})$, and propelling efficiency of the arm stroke $\left(\eta_{\mathrm{p}}\right)$. In master swimmers, the differences between genders may represent an interesting topic of research to find out whether the effects of aging are similar in both genders. However, the body of knowledge about this issue is scarce (16) and few reports included cross-sectional data about their physiologic and biomechanic characteristics (37). Compared with young and elite counterparts, longitudinal research with masters swimmers is reduced and exclusively focused on performance variations based on race time progression (16) and energy cost (38). As far as we can understand, it seems that there is a lack of evidence about energetic and biomechanical adaptations of master swimmers over time (e.g., a full season).

The aim of this research was to analyze the effect of energetic and gender on the performance and biomechanics of master swimmers over 1 season. It was hypothesized that (a) gender influences the performance, (b) energetics influences the performance and biomechanics, and (c) biomechanics influences the performance.

\section{Methods}

\section{Experimental Approach to the Problem}

A longitudinal research design was conducted, with 3 evaluation moments over a season: December $\left(\mathrm{TP}_{1}\right)$, March $\left(\mathrm{TP}_{2}\right)$, and June $\left(\mathrm{TP}_{3}\right)$. Training program consisted in 3 sessions per week, involving low-, medium-, and high-aerobic sets, sprinting sets, and drills. Training averaged $9.0 \pm 1.7 \mathrm{~km} \cdot \mathrm{wk}^{-1}$. Throughout the season, the training of swimmers presented an intensity corresponding to aerobic $\left(\mathrm{TP}_{1}\right.$ : $92.81 \% ; \mathrm{TP}_{2}$ : 90.35\%; $\left.\mathrm{TP}_{3}: 91.36 \%\right)$ and anaerobic capacities $\left(\mathrm{TP}_{1}:\right.$ 7.19\%; $\mathrm{TP}_{2}$ : 9.65\%; $\mathrm{TP}_{3}: 8.64 \%$ ) (Figure 1). The training process was always accompanied by the research team with the coach of the team. The distinction between aerobic and anaerobic loads was carried out taking into account the considerations of Maglischo (22) and using the same procedure detailed in previous studies $(10,24)$. In each TP, the $200-\mathrm{m}$ freestyle performance, $v_{4}$, $\mathrm{La}_{\text {peak, }} \dot{\mathrm{V}}_{2} \mathrm{max}, \mathrm{v}_{200}$, SF, SL, SI, and $\eta_{\mathrm{p}}$ were collected.

\section{Subjects}

Twenty-five subjects were recruited for this research. Eleven female swimmers (at baseline, age: $34.7 \pm 7.3$ years; height:
$1.63 \pm 0.05 \mathrm{~m}$; body mass: $58.5 \pm 5.4 \mathrm{~kg}$; personal record in 200 -m freestyle event: $200.73 \pm 25.02$ seconds) and 14 male swimmers (at baseline, age: $35.6 \pm 7.4$ years; height: $1.76 \pm$ $0.06 \mathrm{~m}$; body mass: $73.7 \pm 8.3 \mathrm{~kg}$; personal record in $200-\mathrm{m}$ freestyle event: $173.00 \pm 31.41$ seconds) volunteered to serve as subjects.

Male and female swimmers, aged 25-50 years, were recruited by detailed announcements at a local swimming club. The following inclusion criteria were considered: (a) male or female, (b) aged 25-50 years, (c) have a background as swimmer participating in national swimming events, and (d) be engaged in a systematic master swimming program. The exclusion criteria included the following: (a) any physical challenge, (b) musculoskeletal injury, pathology, or condition, (c) pregnancy, and (d) more than 3 consecutive weeks of absence during the follow-up period.

All subjects gave their written informed consent before participation. The study was approved by the local ethics committee and is in accordance with the Declaration of Helsinki.

\section{Energetics and Biomechanics Data Collection}

An incremental $5 \times 200-\mathrm{m}$ step test $(25-\mathrm{m}$ pool $)$ was selected to evaluate the swimmers' energetic adaptations (33). The starting velocity was set at approximately 0.3 $\mathrm{m} \cdot \mathrm{s}^{-1}$ less than the swimmer's best performance, representing a low training pace (20). Underwater pacemaker lights (GBK-Pacer; GBK Electronics, Aveiro, Portugal) were placed at the bottom of the swimming pool to control the swimming pace along each lap. Time for each trial was clocked with a stopwatch (SEIKO S141) by an expert evaluator as backup.

Oxygen uptake $\left(\dot{\mathrm{V}}_{2}\right)$ was measured with a backward extrapolation technique, immediately after each trial $\left(\mathrm{Kb}^{2}\right.$;

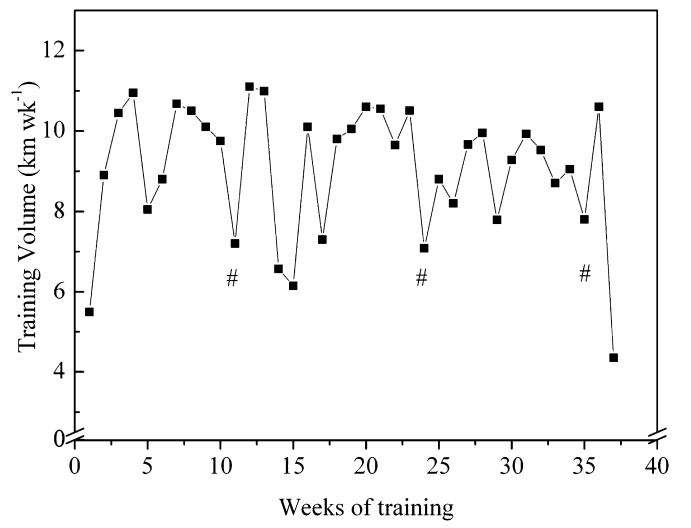

Figure 1. Total weekly volume of training throughout the 3 time periods. \#Test occasions. 
Cosmed, Rome, Italy). The mean error in $\dot{\mathrm{V}}_{2}$ in consecutive evaluations was $1.20 \pm 0.23 \%$. Swimmers were instructed not to breath during the last cycle before touching the wall. After finishing the trial, the swimmer leaned on the wall while an operator fixed a portable mask on his face during all recovery period. The $\mathrm{VO}_{2}$ reached during each step of the protocol was estimated using the backward extrapolation of the oxygen $\left(\mathrm{O}_{2}\right)$ recovery curve. The $\dot{\mathrm{V}}_{2}$ max was considered to be the mean value in the 6 seconds after the $\dot{\mathrm{VO}}_{2}$ detection, during the recovery period (20). The first measurement of $\dot{\mathrm{V}}_{2}$ before the highest $\dot{\mathrm{VO}}_{2}$ value was not considered, because it corresponded to the device adaptation to the sudden change of respiratory cycles and to oxygen uptake. The device adaptation never exceeded 2 seconds $(10,20)$.

Fingertip capillary samples were collected before the $200 \mathrm{~m}$, at the end, and in the third, fifth, and seventh minutes after the protocol to assess lactate concentrations (Accusport; Boherinnger, Mannheim, Germany). The La peak was considered to be the highest blood lactate concentration in postexercise condition (32). The $v_{4}$ was obtained by interpolation of the average lactate value $\left(4 \mathrm{mmol} \cdot \mathrm{l}^{-1}\right)$ on the exponential curve of lactate/speed relationship.

Swimming velocity $(v)$ defined as the ratio between the distance and the time to travel such distance, and it was measured considering the mean value obtained in each lap with a stopwatch (measured between 5 and $20 \mathrm{~m}$ ). The same distance was used to measure SF $(\mathrm{Hz})$, SL (m), SI $\left(\mathrm{m}^{2} \cdot \mathrm{c}^{-1} \cdot \mathrm{s}^{-1}\right)$, and $\eta_{\mathrm{p}}$. The Interclass Correlation Coeficient (ICC) in all biomechanic variables ranged from 0.98 to 0.99 . The SF was recorded manually from 3 consecutive stroke cycles in each lap, with a chrono-frequency meter (Golfinho Sports MC 815, Aveiro, Portugal). Then, SF values were converted to International System Units (i.e., Hz).

The SL was estimated as the ratio between swimming velocity and SF (13). The SI was computed as the product of the velocity of the swimmer during the $15 \mathrm{~m}$ recorded and the corresponding SL (12). The propelling efficiency of the arm stroke $\left(\eta_{\mathrm{p}}\right)$ was estimated as being (39):

$$
\eta_{\mathrm{p}}=\left(\frac{v \times 0.9}{2 \pi \times \mathrm{SF} \times \mathrm{l}}\right) \times \frac{2}{\pi},
$$

where the factor 0.9 takes into account that, in front crawl, about $10 \%$ of forward propulsion is produced by the kicking, $\mathrm{SF}$ is the stroke frequency $(\mathrm{Hz})$, and $l$ is the arm's length $(\mathrm{m})$, being computed trigonometrically, measuring the arm's length and considering the average elbow angles during the insweep of the arm pull, as reported by Zamparo (35). All the energetic and biomechanical values were then estimated at $v_{200}$ performance.

\section{Performance Data Collection}

Swimming performance was assessed based on time lists of the $200-\mathrm{m}$ freestyle event during local, regional, and national competitions. The time between the official event and the testing session took no longer than 2 weeks.

\section{Statistical Procedures}

Standard statistical methods were used for the calculation of the mean and SDs. For the analysis of the statistical effect of energetic and biomechanic variables on performance in each $\mathrm{TP}$, a univariate analysis of covariance (ANCOVA) was used, having as dependent variable the performance, as factor the gender, and SF, SL, SI, $\eta_{\mathrm{p}} \mathrm{La}_{\text {peak }}$, $v_{4}$, and $\mathrm{V}_{2}$ max as covariates. For the analysis of the statistical effect of energetic variables on biomechanic variable in each $\mathrm{TP}$, a multivariate analysis of covariance (MANCOVA) was used, having as dependent variables SF, SL, SI, $\eta_{\mathrm{p}}$, as factor the gender, and $\mathrm{La}_{\text {peak }}, v_{4}$, and $\dot{\mathrm{V}}_{2}$ max as covariates. The normality of the residuals of MANCOVA was checked by applying the Kolmogorov-Smirnov test and the homogeneity of variancecovariance matrix was tested by the BoxMtest $\left(\mathrm{TP}_{1}: \mathrm{M}=\right.$ $30.198, F_{(10,2183.5)}=2.43, p \leq 0.05 ; \mathrm{TP}_{2}: \mathrm{M}=15.722$, $F_{(15,1852.3)}=1.26, p>0.05 ; \mathrm{TP}_{3}: \mathrm{M}=33.830, F_{(10,1852.3)}=$ $2.72, p \leq 0.05)$. When the assumption was not verified $(p \leq$ $0.05)$, it was selected the Pillai's Trace test statistics, while when the assumption was verified $(p>0.05)$, it was selected the Wilks' Lambda. When statistically significant differences were observed, an ANCOVA was estimated for each dependent variable, followed by Bonferroni's post hoc comparison tests. Partial eta squared $\left(\eta_{\mathrm{p}}^{2}\right)$ was selected as effect size index.

\section{Results}

\section{Energetics}

$\dot{\mathrm{V}}_{2} \mathrm{max}, \mathrm{La}_{\text {peak }}$, and $v_{4}$ were higher in males compared with females in all TPs (Figure 2). These differences were significant only for $\mathrm{La}_{\text {peak }}$ in all TPs $\left(\mathrm{TP}_{1}: p=0.02 ; \mathrm{TP}_{2}: p<\right.$ $\left.0.001 ; \mathrm{TP}_{3}: p<0.001\right)$ with a significant and large effect of gender on this variable in $\mathrm{TP}_{3}\left(\eta_{\mathrm{p}}^{2}=0.42, p<0.001\right)$. $\dot{\mathrm{V}}_{2} \max$ increased in male $(8.5,11.1$ and 20.5\%) and female (12.2, 1.2 and $13.5 \%$ ) between $\mathrm{TP}_{1}-\mathrm{TP}_{2}, \mathrm{TP}_{2}-\mathrm{TP}_{3}$, and $\mathrm{TP}_{1}-\mathrm{TP}_{3}$, respectively (Figure 2A). A decrease in $\mathrm{La}_{\text {peak }}$ was determined for males throughout all TPs: $\mathrm{TP}_{1}-\mathrm{TP}_{2}(-3.9 \%)$; $\mathrm{TP}_{2}-\mathrm{TP}_{3}$ $(-2.3 \%)$; $\mathrm{TP}_{1}-\mathrm{TP}_{3}(-6.1 \%)$, whereas $\mathrm{La}_{\text {peak }}$ in females decreased from $\mathrm{TP}_{1}$ to $\mathrm{TP}_{2}(-11.6 \%)$, increased from $\mathrm{TP}_{2}$ to $\mathrm{TP}_{3}(3.1 \%)$, and decreased from $\mathrm{TP}_{1}$ to $\mathrm{TP}_{3}(-8.1 \%)$ (Figure $2 \mathrm{~B})$. An increase in $v_{4}$ was observed throughout the season in both genders: male's $v_{4}$ increased 1.1, 2.2, and 3.3\% between $\mathrm{TP}_{1}-\mathrm{TP}_{2}, \mathrm{TP}_{2}-\mathrm{TP}_{3}$ (in this case significantly), and $\mathrm{TP}_{1}-\mathrm{TP}_{3}$, respectively (Figure $2 \mathrm{C}$ ). Female showed a nonsignificant increase between $\mathrm{TP}_{1}$ and $\mathrm{TP}_{2}(2.28 \%)$, slight increase between $\mathrm{TP}_{2}$ and $\mathrm{TP}_{3}(0.9 \%)$, and a significant increase between $\mathrm{TP}_{1}$ and $\mathrm{TP}_{3}(3.14 \%)$.

A large effect of $v_{4}$ on biomechanic variables was found in all TPs $\left(\mathrm{TP}_{1}: \eta_{\mathrm{p}}^{2}=0.85, p<0.001 ; \mathrm{TP}_{2}: \eta_{\mathrm{p}}^{2}=0.88, p<0.001\right.$; $\left.\mathrm{TP}_{3}: \eta_{\mathrm{p}}^{2}=0.60, p<0.001\right)$. In $\mathrm{TP}_{1}$, we observed that $v_{4}$ has a large effect on SI $\left(\eta_{\mathrm{p}}^{2}=0.56, p<0.001\right)$, followed by $\eta_{\mathrm{p}}$ $\left(\eta_{\mathrm{p}}^{2}=0.47, p<0.001\right)$ and SL $\left(\eta_{\mathrm{p}}^{2}=0.38, p<0.001\right)$. In $\mathrm{TP}_{2}$, data showed a large effect of $v_{4}$ on SI $\left(\eta_{\mathrm{p}}^{2}=0.58, p<0.001\right)$ 

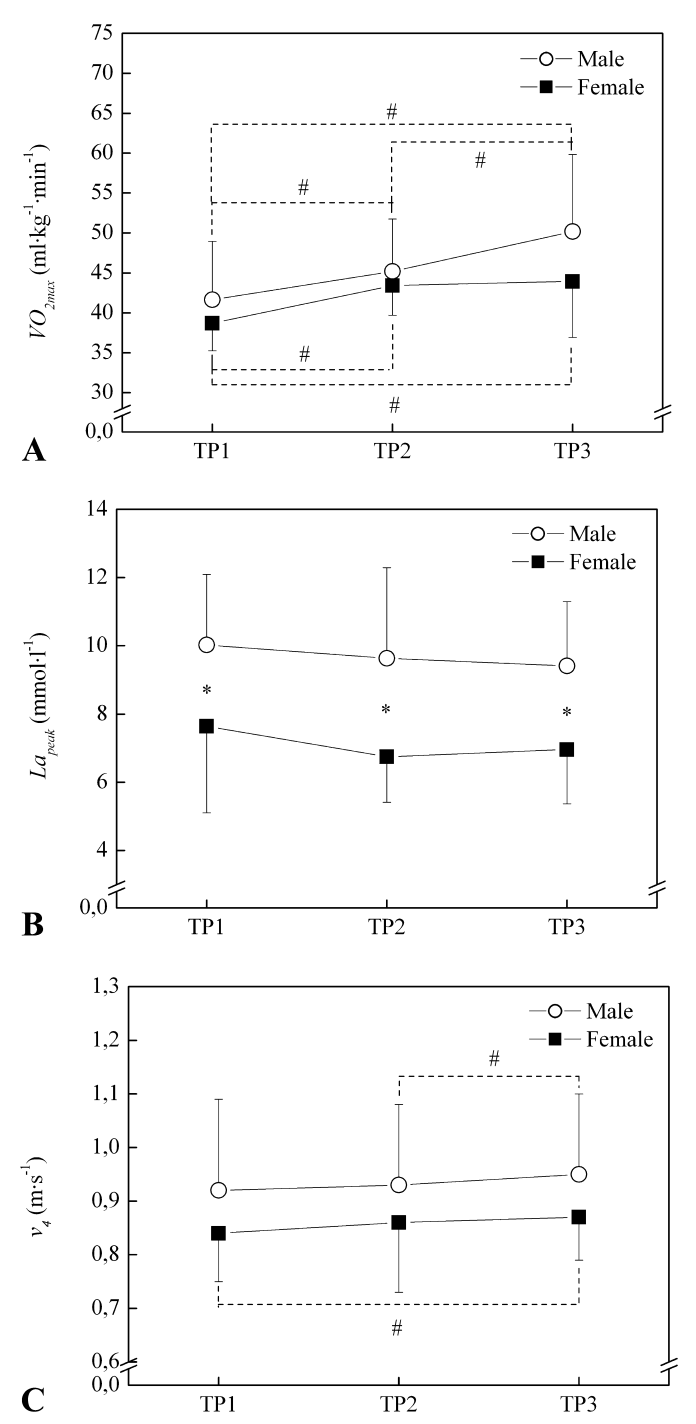

Figure 2. Mean $\pm S D$ values of $\mathrm{VO}_{2} \max (\mathrm{A}), \mathrm{La}_{\text {peak }}(\mathrm{B})$, and $v_{4}(\mathrm{C})$ in the 3 TPs. *Significant differences in $\mathrm{La}_{\text {peak }}$ between males and females $\left(\mathrm{TP}_{1}: p=0.02 ; \mathrm{TP}_{2}: p<0.001 ; \mathrm{TP}_{3}: p<0.001\right)$. \#Significant differences in $v_{4}$ male between $\mathrm{TP}_{2}$ and $\operatorname{TP}_{3}(p=0.02)$ and female between $\mathrm{TP}_{1}$ and $\mathrm{TP}_{3}(p=0.02)$; in $\mathrm{V}_{2}$ max male between $\mathrm{TP}_{1}$ and $\mathrm{TP}_{2}$ $(p=0.01), \operatorname{TP}_{2}$ and $\operatorname{TP}_{3}(p=0.01)$, and $\operatorname{TP}_{1}$ and $\mathrm{TP}_{3}(p<0.001)$; and $\mathrm{VO}_{2}$ max female between $\mathrm{TP}_{1}$ and $\mathrm{TP}_{2}(p=0.01)$, and $\mathrm{TP}_{1}$ and $\mathrm{TP}_{3}$ $(p=0.02)$

and $\eta_{\mathrm{p}}\left(\eta_{\mathrm{p}}^{2}=0.32, p=0.01\right)$, and a moderate-sized effect on SL $\left(\eta_{\mathrm{p}}^{2}=0.24, p=0.02\right)$. In the last TP, $v_{4}$ has a large effect on SL $\left(\eta_{\mathrm{p}}^{2}=0.52, p<0.001\right)$, followed by SI $\left(\eta_{\mathrm{p}}^{2}=0.50, p<\right.$ $0.001)$ and $\eta_{\mathrm{p}}\left(\eta_{\mathrm{p}}^{2}=0.50, p<0.001\right)$. $\mathrm{La}_{\text {peak }}$ and $\dot{\mathrm{V}}_{\mathrm{O}_{2}} \max$ did not have a significant effect on biomechanic variables in all TPs.

\section{Biomechanics}

Males presented a higher SF only in $\mathrm{TP}_{1}$ (Figure 3). In the other 2 TPs, females obtained a higher SF, although these

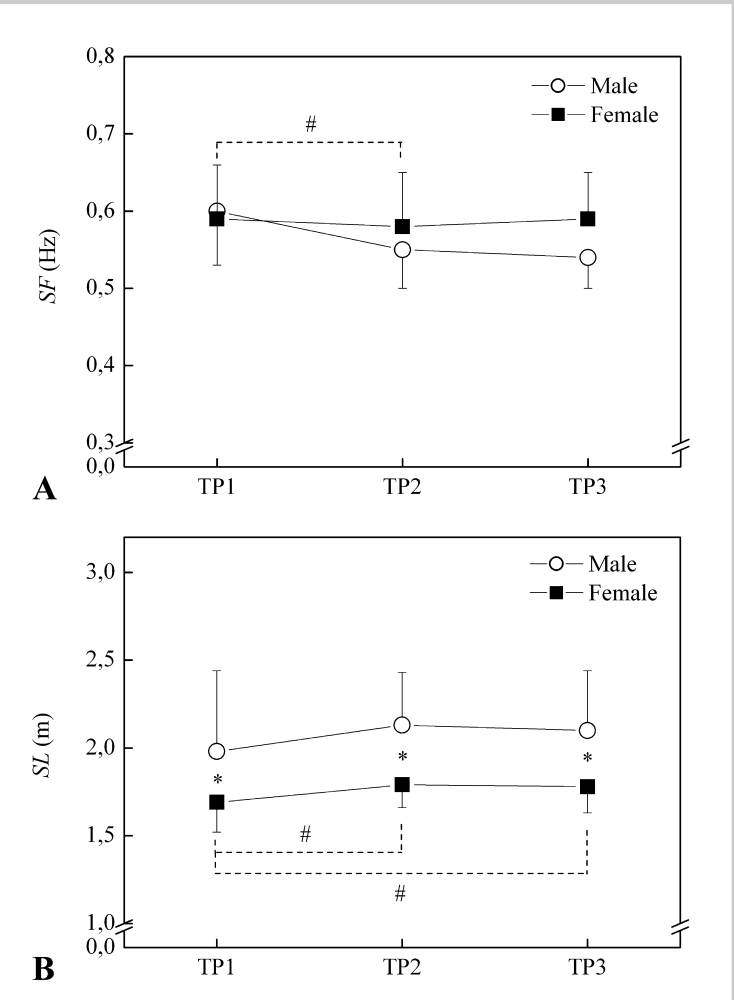

Figure 3. Mean $\pm S D$ values of $S F(A)$ and $S L(B)$ in the 3 TPs. *Significant differences in SL between males and females ( $\mathrm{TP}_{1}: p=0.04$; $\left.\mathrm{TP}_{2}: p<0.001 ; \mathrm{TP}_{3}: p<0.001\right)$; \#Significant differences in females $\mathrm{SL}$ between $\mathrm{TP}_{1}$ and $\mathrm{TP}_{2}(p<0.001)$, and $\mathrm{TP}_{1}$ and $\mathrm{TP}_{3}(p=0.03) . \mathrm{SF}=$ stroke frequency; $\mathrm{SL}=$ stroke length.

differences were not significant, with a small effect size over the season $\left(\mathrm{TP}_{1}: \eta_{\mathrm{p}}^{2}=0.04 ; \mathrm{TP}_{2}: \eta_{\mathrm{p}}^{2}=0.17 ; \mathrm{TP}_{3}: \eta_{\mathrm{p}}^{2}=0.11\right)$. In females, $\mathrm{SF}$ decreased between $\mathrm{TP}_{1}$ and $\mathrm{TP}_{2}(-1.9 \% ; p=$ $0.04)$, increased between $\mathrm{TP}_{2}$ and $\mathrm{TP}_{3}(2.2 \%)$, and between $\mathrm{TP}_{1}$ and $\mathrm{TP}_{3}(0.3 \%)$. In males a nonsignificant decrease was observed throughout the season: $-8.6,-0.5$, and $-9.1 \%$ (Figure $3 \mathrm{~A})$. Stroke length was higher in males compared with females in all TPs (TP1: $p=0.04 \mathrm{TP}_{2}: p<0.001 ; \mathrm{TP}_{3}: p<$ $0.001)$ with a moderate and large effect in $\mathrm{TP}_{2}\left(\eta_{\mathrm{p}}^{2}=0.29\right)$ and $\mathrm{TP}_{3}\left(\eta_{\mathrm{p}}^{2}=0.37\right)$, respectively (Figure $\left.3 \mathrm{~B}\right)$. In both genders, $\mathrm{SL}$ increased from $\mathrm{TP}_{1}-\mathrm{TP}_{2}$ (male: $7.7 \%$; female: $p<0.001 ; 6.0 \%$ ) and slightly decreased from $\mathrm{TP}_{2}$ to $\mathrm{TP}_{3}$ (male: $-1.5 \%$; female: $-0.7 \%)$. From the first to the last TP, SL increased $6.1 \%$ in male and $5.2 \%$ in female group $(p=0.03)$.

Males presented a higher SI and $\eta_{\mathrm{p}}$ than females in all TPs (Figure 4). However, these gender differences were only significant for $\mathrm{SI}$ in $\mathrm{TP}_{1}(p=0.01)$ and $\mathrm{TP}_{2}(p<0.001)$, with a moderate-sized effect in $\mathrm{TP}_{2}\left(\eta_{\mathrm{p}}^{2}=0.25\right)$. In males, a nonsignificant increase was observed in SI throughout the season: $5.8,1.1$, and $6.9 \%$. In females, SI presented an increase between $\mathrm{TP}_{1}$ and $\mathrm{TP}_{2}(9.5 \% ; p=0.04), \mathrm{TP}_{2}$ and $\mathrm{TP}_{3}(1.0 \%)$, and between $\mathrm{TP}_{1}$ and $\mathrm{TP}_{3}(10.6 \% ; p=0.03)$ (Figure 4A). Nonsignificant differences were found in $\eta_{\mathrm{p}}$ between genders 


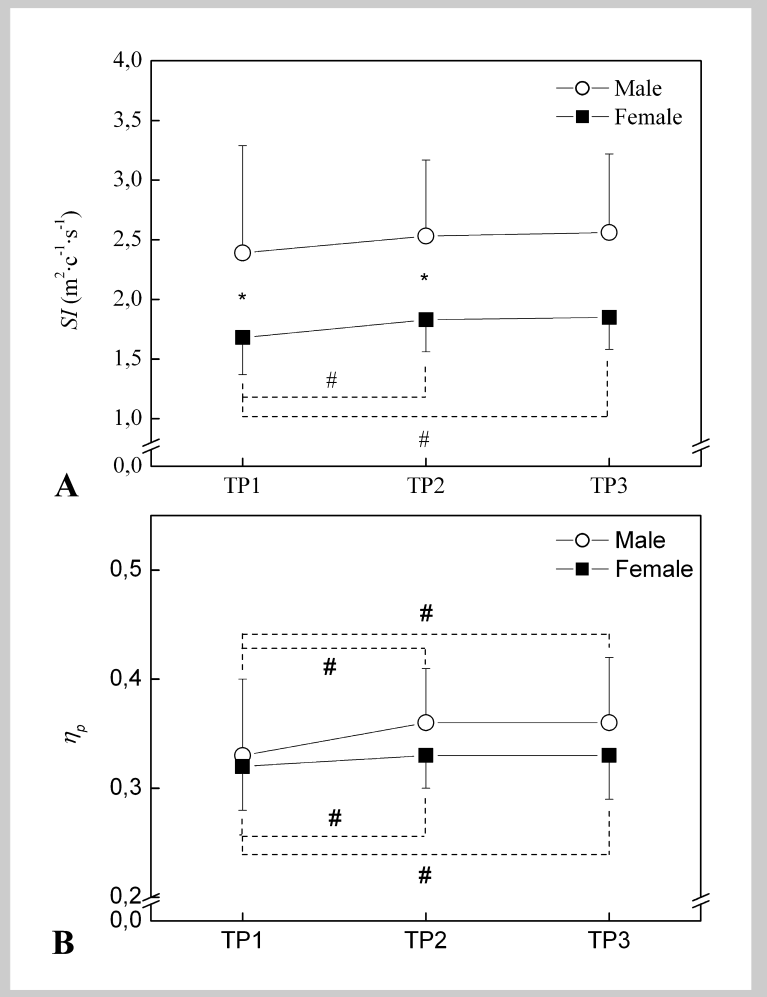

Figure 4. Mean $\pm S D$ values of $S I(A)$ and $\eta_{p}(B)$ in the 3 TPs. *Significant differences in SI between males and females (TP $1: p=0.01$; $\left.\mathrm{TP}_{2}: p<0.001\right)$. \#Significant differences in female, $\mathrm{SI}$ between $\mathrm{TP}_{1}$ and $\operatorname{TP}_{2}(p<0.001)$, and $\operatorname{TP}_{1}$ and $\operatorname{TP}_{3}(p<0.001)$; in male, $\eta_{\mathrm{p}}$ between $\mathrm{TP}_{1}$ and $\operatorname{TP}_{2}(p=0.01)$, and $\operatorname{TP}_{1}$ and $\operatorname{TP}_{3}(p=0.02)$, and in female, $\eta_{\mathrm{p}}$ between $\operatorname{TP}_{1}$ and $\operatorname{TP}_{2}(p=0.01)$, and $\mathrm{TP}_{1}$ and $\mathrm{TP}_{3}(p=0.03) . \mathrm{SI}=$ stroke index.

in all TPs (Figure 4B). In both genders, $\eta_{\mathrm{p}}$ increased from $\mathrm{TP}_{1}$ to $\mathrm{TP}_{2}$ (male: $8.9 \%, p=0.01$; female: $5.8 \%, p=0.01$ ), decreasing slightly from $\mathrm{TP}_{2}$ to $\mathrm{TP}_{3}$ (male: $-0.8 \%$; female: $-0.5 \%)$.

In $\mathrm{TP}_{1}$, nonsignificant effect of gender on biomechanic variables was found. In $\mathrm{TP}_{2}$, the gender influence was greater in SL, followed by SI, both with a medium-size effect $\left(\eta_{\mathrm{p}}^{2}=\right.$ $0.29, p=0.01$ and $\eta_{\mathrm{p}}^{2}=0.26, p=0.02$, respectively). $\mathrm{TP}_{3}$ presented a significant large effect-sized in SL $\left(\eta_{\mathrm{p}}^{2}=0.37\right)$.

\section{Performance}

Comparing both genders, males had always better performances than females $\left(\mathrm{TP}_{1}: p=0.02, \eta_{\mathrm{p}}^{2}=0.11 ; \mathrm{TP}_{2}: p=0.04\right.$, $\left.\eta_{\mathrm{p}}^{2}=0.02 ; \mathrm{TP}_{3}: p=0.01, \eta_{\mathrm{p}}^{2}=0.03\right)$. The males presented a nonsignificant improvement in the performance over the season $\left(\mathrm{TP}_{1}-\mathrm{TP}_{2}:-1.5 \% ; \mathrm{TP}_{2}-\mathrm{TP}_{3}:-2.0 \% ; \mathrm{TP}_{1}-\mathrm{TP}_{3}\right.$ : $-3.5 \%)$, whereas, in females, significant improvements were observed in $\mathrm{TP}_{1}-\mathrm{TP}_{2}(-3.8 \% ; p<0.001)$ and $\mathrm{TP}_{1}-\mathrm{TP}_{3}$ $(-5.7 \% ; p<0.001)$ (Figure 5).

\section{Performance Determinants}

A large effect of SF, SL, SI, and $\eta_{\mathrm{p}}$ on performance in the 3 TPs was found. In $\mathrm{TP}_{1}$, a moderate-sized effect of $\mathrm{SF}$

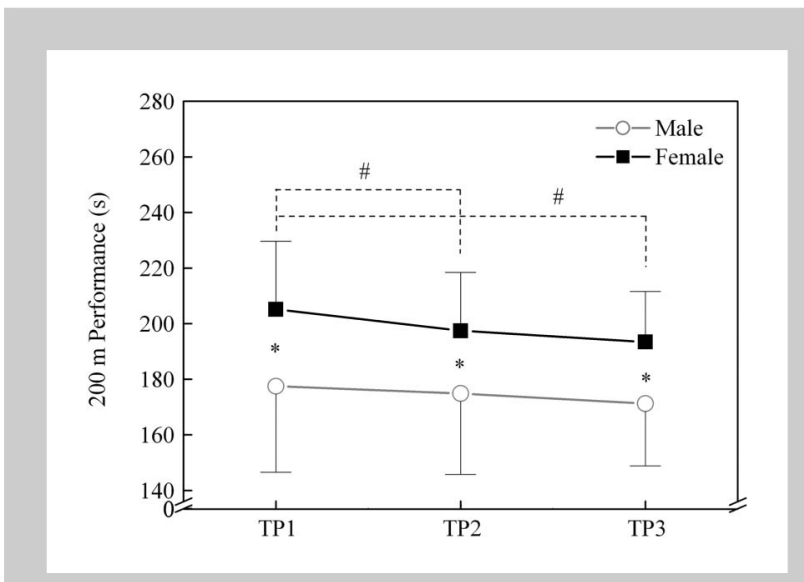

Figure 5. Mean $\pm S D$ values of the 200-m freestyle performance in the 3 TPs. *Significant differences between genders $\left(\mathrm{TP}_{1}: p=0.02 ; \mathrm{TP}_{2}\right.$ : $\left.p=0.04 ; \mathrm{TP}_{3}: p=0.01\right)$. \#Significant differences in female $200-\mathrm{m}$ performance between $\mathrm{TP}_{1}$ and $\mathrm{TP}_{2}(p<0.001)$, and $\mathrm{TP}_{1}$ and $\mathrm{TP}_{3}$ $(p<0.001)$

$\left(\eta_{\mathrm{p}}^{2}=0.24, p=0.04\right)$ and $\eta_{\mathrm{p}}\left(\eta_{\mathrm{p}}^{2}=0.28, p=0.03\right)$, a large effect of SL $\left(\eta_{\mathrm{p}}^{2}=0.46, p<0.001\right)$ and SI $\left(p<0.001, \eta_{\mathrm{p}}^{2}=0.78\right)$. In $\mathrm{TP}_{2}$, a large effect of SI $\left(\eta_{\mathrm{p}}^{2}=0.37, p=0.01\right)$ was found. In $\mathrm{TP}_{3}$ a large effect of SI $\left(\eta_{\mathrm{p}}^{2}=0.32, p=0.01\right)$ was found. Concerning the effect of energetic variables on performance, a moderate-sized effect of $v_{4}$ on performance was found $\left(\eta_{\mathrm{p}}^{2}=0.23, p=0.04\right)$ in $\mathrm{TP}_{3}$. There was a nonsignificant effect of gender on performance over the season.

\section{Discussion}

The aim of this study was to compare the changes in performance, energetics, and biomechanics of male and female master swimmers and to analyze the effect of the energetic variables and gender on performance and biomechanical variables within a season. Males presented better performance and higher SL, SI, and $\mathrm{La}_{\text {peak }}$ values than females. No differences between genders were found in SF, $\eta_{\mathrm{p}}, v_{4}$, and $\dot{\mathrm{V}}_{2} \max$. Stroke frequency, SL, SI, $\eta_{\mathrm{p}}$, and $v_{4}$ influence performance.

The glycolytic metabolism depends on muscle mass involved, such as on the proportion of fast-twitch fibers (7). With men having greater skeletal muscle mass than women, it is expected that higher lactate production, and the large effect of gender on $\mathrm{La}_{\text {peak }}$ found in $\mathrm{TP}_{3}$, emphasizes that difference. No significant increase in $\mathrm{La}_{\text {peak }}$ was found throughout the season in both genders. The assessment of $\mathrm{La}_{\text {peak }}$ is related to anaerobic capacity and the absence of improvements is probably due to the lower percentage of anaerobic workout and to the decrease found in anaerobic capacity with aging (26). The values reported for both genders were lower than those obtained by Benelli et al. (7) $\left(10.8 \pm 2.8 \mathrm{mmol} \cdot \mathrm{l}^{-1}\right.$ in female, and $14.2 \pm 2.5 \mathrm{mmol} \cdot \mathrm{l}^{-1}$ in male), probably related with different experiences and performance level of the samples, including from elite 
swimmers to "weekend athletes" who sporadically train and compete.

Methods to quantify the release of anaerobic energy are less accurate than the aerobic energy becuase it is an intracellular process with little reliance on central processes (18). For this reason, a universally accepted method cannot be found, but the literature reports a variety of procedures that have been used, highlighting the peak blood lactate concentration after exercise and accumulated oxygen deficit. The advantages of peak blood lactate concentration after exercise benefits from ease of implementation and from the existence of studies that showed the reliability of this method $(5,9,36)$, even in low-intensity bouts, as occurred in the beginning of the test (3).

The accumulated oxygen deficit method is based in 2 assumptions (27): (a) establishment of the submaximal energy cost (by the linear relation between $\dot{\mathrm{V}}_{2}$ /velocity) and (b) estimative of the supramaximal energy cost by linear extrapolation of the submaximal energy cost. Regarding to point (a), this assumption requires the measurement of the steady state $\dot{\mathrm{VO}}_{2}$ at several intensities. For this, it is necessary to perform a submaximal, discontinuous, and progressive intensity test. The first main issue of this method arises at this point: define the optimal duration of each submaximal exercise to avoid underestimates or overestimates the submaximal energy cost. The second issue is related with the estimative of the supramaximal energy cost by linear extrapolation of the submaximal energy cost (point (b)). Some authors suggest that the relationship between $\mathrm{VO}_{2}$ and the intensity is not linear, which may limit the use of linear extrapolation. Questions as to the existence of linearity in the $\dot{\mathrm{V}}_{2}$ intensity relationship consubstantiate in the alleged decrease of efficiency, the effect of exercise intensity increase.

The accumulated oxygen deficit method includes also a second test: supramaximal continuous, until exhaustion test to calculate the accumulated oxygen deficit as the difference between the total energy demand and the accumulated $\dot{\mathrm{V}}_{2}$. The requirement to perform 2 tests makes this method more time consuming and complex contrasting with the ease of the use of the peak blood lactate concentration after exercise. After analyzing the advantages and disadvantages of the 2 methods, we decided to use the peak blood lactate concentration after exercise.

The $v_{4}$ is influenced by the volume of training: higher training volume leads to a greater aerobic capacity. Therefore, and since the training stimulus is the same for both genders, the absence of differences between male and female is not surprising. Generally, the increase in $v_{4}$ happens in the first months of training due to volume increase. However, our sample was engaged in a high percentage of aerobic training pace throughout the season. The increase in $\dot{\mathrm{V}}_{2}$ max for both genders may be due to that training, with a minor focus on strength, speed, and power tasks as occurs in young and elite swimmers (34).

A swimming event is composed by 4 moments: start, swim, turn, and finish. The use of the snorkel might impose some constraints during some of these moments, especially during the start and turn moments (4). For example, the gliding phases after the start and turns are usually less effectives when the swimmers use the snorkel since the duration and depth of the glide after takeoff are minimized (4). Moreover, the rolling turning technique must be changed to the open turn. Another constraint of the use of the Aquatrainer snorkel may be the increase of the drag force up to $10 \%$ (19) which, without a concomitant increase of the propulsive force will lead to a decrease in velocity, and consequently, in the swimming performance. Some studies reported no significant differences in stroke mechanics between swim with and without the Aquatrainer snorkel $(2,28)$. Thus, the significant changes in the performance may be more related, not with swimming, but with the other moments of the swimming event, such as the start and turns. Despite the improvement verified in the snorkel reported by Baldari et al. (2), such as more comfortable mouthpiece and head connection, underwater stability of the tubes and a better freedom of movement due the higher flexibility of the system, the constraints related with start and turns remain, whereby we decided to use the method of the extrapolation of $\dot{\mathrm{V}}_{2}$ kinetics.

The $v_{4}$ has a large effect on performance and in biomechanics variables, being the effect size higher in SI, followed by $\eta_{\mathrm{p}}$ and SL. Considering that the assessment of $v_{4}$ is important in determining the aerobic capacity of the swimmers, the higher influence of $v_{4}$ on performance highlights the importance of aerobic contribution for the total energy expenditure in the $200-\mathrm{m}$ race. The large effect found of $v_{4}$ on SI, SL, and $\eta_{\mathrm{p}}$, may be caused by the aerobic loads, that allows to swim at low velocities and focus on technical aspects of the stroke mechanics, improving their technical ability.

Females presented nonsignificant higher values of $\mathrm{SF}$ than males in $\mathrm{TP}_{2}$ and $\mathrm{TP}_{3}$. The $\mathrm{SF}$ is dependent of the limb's kinematics (6) and the surface area of propulsive segments (25). A negative nonsignificant relationship between SF and arm span was found in another study (30). However, these gender differences in SF were nonsignificant, which was corroborated by the absence of a significantly effect-sized of gender on SF in the 3 TP. Female swimmers presented a decrease in $\mathrm{SF}$ between $\mathrm{TP}_{1}$ and $\mathrm{TP}_{2}$, which may be related with training. The swimmers may have learned how to swim with fewer strokes and to be more effective as demonstrated by the improvement found in $\eta_{\mathrm{p}}$ over the season. Comparing with Zamparo's data (35), the difference found may be due to the different methodology used to calculate SF. Zamparo used the average time taken to complete 5 strokes, whereas we used the average time to complete 3 strokes (35).

The SL is related with the anthropometric characteristics, for example, height, arm span, and arm length (30). In our study, males were taller than females, whereby the greater SL of males may be related with their anthropometric 
values. Moreover, SL is related to the ability to exert powerful and effective stroke in water. The power developed per cycle by males is higher than females because the latter have less muscle strength and power (21), in opposition to the higher muscle mass in males (15).

Female SL increased from $\mathrm{TP}_{1}$ to $\mathrm{TP}_{2}$ and $\mathrm{TP}_{1}$ to $\mathrm{TP}_{3}$, which would mean that, with training, the stroke became more powerful and effective and probably contributed to the improved performance. Zamparo's results (35) were different, with males reaching lower values of SL and females presenting higher values than ours, possibly because of the different anthropometrics and test performed. The higher SF and lower SL found by Favaro and Lima (17) may be due to the different race used $(50 \mathrm{~m})$. In shorter distances, $v$ increases at expense of the increase of SF and not SL. Knowing that $\mathrm{SL}$ is larger at a slow velocity and tends to decrease at maximal velocity values (35) and analyzing the results of Zamparo et al. (37), the lower SF values and higher SL were probably due to the different test used, where $v$ was achieved by a smaller SF and a larger SL.

The anthropometrics, specifically the height, could also influence the higher SI values presented by male swimmers. These results were highlighted by the moderate effect of gender on SL and SI. Females presented an increase in SI throughout the season that represented an improvement in the ability to swim higher distances within a stroke cycle at similar velocities (12). The absence of significant increase in male SI (and SL) probably means that male presented a better swim technique compared with women, being more difficult to observe changes in stroke mechanics.

The $\eta_{\mathrm{p}}$ was higher (no significant) in males compared with females in all TPs. As indicated by equation $1, \eta_{\mathrm{p}}$ is directly related with $v$ and inversely related with SF. Because males presented better performances than females, these results are expected. Moreover, the results revealed that females obtained higher (nonsignificant) values of $\mathrm{SF}$ than males in 2 periods of the season $\left(\mathrm{TP}_{2}\right.$ and $\left.\mathrm{TP}_{3}\right)$, which may also justify the higher values of $\eta_{p}$ found in males. The different values obtained by Zamparo (35) could be attributed to the anthropometric characteristics of the subjects, as a shorter shoulder-to-hand distance lead to higher $\eta_{\mathrm{p}}$ : the swimmers of our study presented lower values of arm length compared with the Zamparo's study (35) $(0.60 \pm 0.03$ and $0.57 \pm 0.01 \mathrm{~m}$ vs. $0.73 \pm 0.06 \mathrm{~m}$, respectively).

Differences in the $200-\mathrm{m}$ performance between genders may be attributed to both energetic and biomechanics factors. The energetics focuses on the ability of the muscle cells to provide energy by 3 distinct, but operating together, metabolic pathways (aerobic, anaerobic lactic, and anaerobic alactic) (18). The contribution of each one to release energy for competitive swimming depends on the exercise intensity and duration. The main energy source for the $200 \mathrm{~m}$ is aerobic, followed by the anaerobic lactic system. $\mathrm{La}_{\text {peak }}$, as a measure of anaerobic energy release during exercise, suggest a higher anaerobic contribution in the male group compared with females. Regarding the biomechanics, the higher values of SL, SI, and $\eta_{\mathrm{p}}$ in males may ascribe the better performane compared with female.

Swimming performance depends on the interaction between physiological and biomechanical factors (4) and therefore, the improvement in female swimmers from $\mathrm{TP}_{1}$ to $\mathrm{TP}_{2}$ and $\mathrm{TP}_{1}$ to $\mathrm{TP}_{3}$ may be due to the variations in those variables over the season. The influence that the technical aspects had on performance rather the energetics may be a consequence of the structural and functional impairment that occurs with advancing age in most physiological systems (8), associated to the minor engaging in regular exercise (14) and the characteristics of training (predominantly aerobic). Thus, it seems that, in this age group, the swimming technique is the major determinant for performance.

It can be pointed as main limitations of the study: (a) the subjects performed oriented instead of fitness oriented, (b) the slightly effects in middle-aged swimmers (compared with advanced ages), (c) the training frequency was not controlled, and (d) the no use of more sophisticated biomechanical analysis (i.e., videometry) because it was too time consuming and complex to be conducted.

\section{Practical Applications}

Considering the masters swimmers of this study, we found that it is possible to improve performance of swimmers in this age group, which may indicate that regular physical exercise ( 3 times per week, lasting 1 hour and 30 minutes per session), may be sufficient to mitigate the loss of the physiological functional capacity that occurs with increasing age.

In this age group, the performance seems to be more dependent on technical than energetic factors whereby, the training should aim to preserve the energetic factors as much as possible, and at the same time, develop the technical skills. Thus, the training should include a higher percentage of technical drills to enhance technical performance of the swimmers. The focus could be to associate technical training with aerobic and anaerobic tasks, allowing the swimmer to increase technical efficiency.

\section{ACKNowledgments}

The authors thank all the swimmers and their coaches who participated in this study. This work was supported by University of Beira Interior and Santander Totta bank (UBI/ FCSH/Santander/2010). The authors declare that they have no conflict of interest.

\section{REFERENCES}

1. Anderson, ME, Hopkins, WG, Roberts, AD, and Pyne, DB. Monitoring seasonal and long-term changes in test performance in elite swimmers. Eur J Sport Sci 6: 145-154, 2006.

2. Baldari, C, Fernandes, RJ, Meucci, M, Ribeiro, J, and Guidetti, L. Is the new AquaTrainer snorkel Valid for $\mathrm{VO}_{2}$ assessment in swimming? Int J Sport Med 34: 336-344, 2013. 
3. Baldari, C, Videira, M, Madeira, F, Sergio, J, and Guidetti, L. Blood lactate removal during recovery at various intensities below the individual anaerobic threshold in triathletes. J Sports Med Phys Fitness 45: 460-466, 2005.

4. Barbosa, TM, Bragada, JA, Reis, VM, Marinho, DA, Carvalho, C, and Silva, AJ. Energetics and biomechanics as determining factors of swimming performance: Updating the state of the art. J Sci Med Sport 13: 262-269, 2010.

5. Barbosa, TM, Keskinen, KL, Fernandes, R, Colaço, P, Carmo, C, and Vilas-Boas, JP. Relationships between energetic, stroke determinants, and velocity in butterfly. Int J Sports Med 26: 841-846, 2005.

6. Barbosa, TM, Marinho, DA, Costa, MJ, and Silva, AJ. Biomechanics of competitive swimming strokes. In: Biomechanics in Applications. $\mathrm{K}$. Vaclav, ed. Vienna: Austria, InTech, 2011. pp: 367-388.

7. Benelli, P, Ditroilo, M, Forte, R, De Vito, G, and Stocchi, V. Assessment of post-competition peak blood lactate in male and female master swimmers aged 40-79 years and its relationship with swimming performance. Eur J Appl Physiol 99: 685-693, 2007.

8. Bongard, V, McDermott, AY, Dallal, GE, and Schaefer, EJ. Effects of age and gender on physical performance. Age 29: 77-85, 2007.

9. Capelli, C, Pendergast, DR, and Termin, B. Energetics of swimming at maximal speeds in humans. Eur J Appl Physiol 78: 385-393, 1998.

10. Costa, MJ, Bragada, JA, Mejias, JE, Louro, H, Marinho, DA, Silva, AJ, and Barbosa, TM. Tracking the performance, energetics and biomechanics of international versus national level swimmers during a competitive season. Eur J Appl Physiol 112: 811-820, 2012.

11. Costa, MJ, Marinho, DA, Reis, VM, Silva, AJ, Marques, MC, Bragada, JA, and Barbosa, TM. Tracking the performance of worldranked swimmers. J Sport Sci Med 9: 411-417, 2010.

12. Costill, DL, Kovaleski, J, Porter, D, Kirwan, J, Fielding, R, and King, D. Energy expenditure during front crawl swimming: Predicting success in middle-distance events. Int J Sport Med 6: 266270, 1985.

13. Craig, A, Skehan, P, Pawelczyk, J, and Boomer, W. Velocity, stroke rate, and distance per stroke during elite swimming competition. Med Sci Sports Exerc 17: 625-634, 1985.

14. DiPietro, L. Physical activity in aging: Changes in patterns and their relationship to health and function. J Gerontol A Biol Sci Med Sci 56: 13-22, 2001.

15. Doherty, TJ. The influence of aging and sex on skeletal muscle mass and strength. Curr Opin Clin Nutr Metab Care 4: 503-508, 2001.

16. Donato, AJ, Tench, K, Glueck, DH, Seals, DR, Eskurza, I, and Tanaka, H. Declines in physiological functional capacity with age: A longitudinal study in peak swimming performance. J Appl Physiol 94: 764-769, 2003

17. Favaro, $\mathrm{O}$ and Lima, FT. Influence of the age in the performance, stroke rate and stroke length in masters male swimmers of the 50 meters freestyle. Braz J Sci Mov 13: 67-72, 2005.

18. Gastin, PB. Energy system interaction and relative contribution during maximal exercise. Sport Med 31: 725-741, 2001.

19. Kjendlie, PL, Stallman, R, and Gundersen, JS. Influences of a breathing valve on swimming technique. In: Biomechanics and Medicine in Swimming. IX. J.C. Chatard, ed. Saint-Etienne, France, University of Saint Etienne, 2003. pp: 22-30.

20. Laffite, LP, Vilas-Boas, JP, Demarle, A, Silva, J, Fernandes, R, and Billat, VL. Changes in physiological and stroke parameters during a maximal $400-\mathrm{m}$ free swimming test in elite swimmers. Can J Appl Physiol 29: S17-S31, 2004.
21. Macaluso, A and Vito, G. Muscle strength, power and adaptations to resistance training in older people. Eur J Appl Physiol 91: 450-472, 2004.

22. Maglischo, E. Srwimming Fastest. Champaign, IL: Human Kinetics Books, 2003.

23. Maharam, LG, Bauman, PA, Kalman, D, Skolnik, H, and Perle, SM. Masters athletes: Factors affecting performance/ athletes veterans: Les facteurs affectant la performance. Sport Med 28: 273-285, 1999.

24. Morais, JE, Garrido, ND, Marques, MC, Silva, AJ, Marinho, DA, and Barbosa, TM. The influence of anthropometric, kinematic and energetic variables and gender on swimming performance in youth athletes. J Hum Kinet 39: 203-211, 2013.

25. Pelayo, P, Sidney, M, Kherif, T, Chollet, D, and Tourny, C. Stroking characteristics in freestyle swimming and relationship with anthropometric characteristics. J Appl Biomech 12: 197-206, 1996.

26. Reaburn, $P$ and Dascombe, B. Anaerobic performance in masters athletes. Eur Rev Aging Phys Act 6: 39-53, 2009.

27. Reis, VM, Marinho, DA, Policarpo, FB, Carneiro, AL, Baldari, C, and Silva, AJ. Examining the accumulated oxygen deficit method in front crawl swimming. Int J Sports Med 31: 421-427, 2010.

28. Rodríguez, FA, Keskinen, KL, Kusch, M, and Hoffmann, U. Validity of a swimming snorkel for metabolic testing. Int J Sports Med 29: $120-128,2008$.

29. Rubin, RT and Rahe, RH. Effects of aging in masters swimmers: 40Year review and suggestions for optimal health benefits. Open Access J Sport Med 1: 39-44, 2010.

30. Santos, S. Relationship among anthropometric characteristics, stroke frequency and stroke length in Brazilian elite swimmers. In: $X V I$ International Symposium on Biomechanics in Sports. H.J. Riehle and M.M. Vieten, ed. Konstanz, Germany, UVK-Universitätsverlag Konstanz, 1998. pp. 251-254.

31. Tantrum, $M$ and Hodge, K. Motives for participating in masters swimming. New Zeal J Heal Phys Educ Recreat 26: 3-7, 1993.

32. Termin, B and Pendergast, DR. Training using the stroke frequencyvelocity relationship to combine biomechanical and metabolic paradigms. J Swim Res 14: 9-17, 2000.

33. Thanopoulos, V. The 5 X $200 \mathrm{~m}$ step test lactate curve model: Gender specific characteristics in elite Greek senior freestyle swimmers. Serbian J Sport Sci 4: 153-160, 2010.

34. Weir, PL, Kerr, T, Hodges, NJ, McKay, SM, and Starkes, JL. Master swimmers: How are they different from younger elite swimmers? an examination of practice and performance patterns. J Aging Phys 10: 41-63, 2002.

35. Zamparo, P. Effects of age and gender on the propelling efficiency of the arm stroke. Eur J Appl Physiol 97: 52-58, 2006.

36. Zamparo, P, Capelli, C, and Pendergast, D. Energetics of swimming: A historical perspective. Eur J Appl Physiol 111: 367-378, 2011.

37. Zamparo, P, Gatta, G, Dall'Ora, A, Toneatto, A, and Cortes, M. The determinants of performance in master swimmers: A cross-sectional study on the age-related changes in propelling efficiency, hydrodynamic position and energy cost of front crawl. Eur J Appl Physiol 112: 3949-3957, 2012.

38. Zamparo, P, Gatta, G, and Prampero, PE. The determinants of performance in master swimmers: An analysis of master world records. Eur J Appl Physiol 112: 3511-3518, 2012.

39. Zamparo, P, Pendergast, DR, Mollendorf, J, Termin, A, and Minetti, AE. An energy balance of front crawl. Eur J Appl Physiol 94: 134-144, 2005 